\title{
An Epidemiological Model to Find out Factors Associated with Nodal Involvement among Indian Oral Cancer Patients
}

\author{
Vishwajeet Singh ${ }^{1}$, SVS Deo ${ }^{2}$, Sada Nand Dwivedi ${ }^{*}$, Maroof A. Khan ${ }^{1}$ \\ ${ }^{1}$ Department of Biostatistics, All India Institute of Medical Sciences, New Delhi, India \\ ${ }^{2}$ Department of Surgical Oncology, Dr BRA-IRCH, All India Institute of Medical Sciences, New Delhi, India \\ Email: ^dwivedi7@hotmail.com, dwivedi7@gmail.com,dwivedi7@aiims.edu
}

How to cite this paper: Singh, V., SVS Deo, Dwivedi, S.N. and Khan, M.A. (2018) An Epidemiological Model to Find out Factors Associated with Nodal Involvement among Indian Oral Cancer Patients. Open Journal of Epidemiology, 8, 117-129. https://doi.org/10.4236/ojepi.2018.83010

Received: July 10, 2018

Accepted: August 11, 2018

Published: August 14, 2018

Copyright (c) 2018 by authors and Scientific Research Publishing Inc. This work is licensed under the Creative Commons Attribution International License (CC BY 4.0).

http://creativecommons.org/licenses/by/4.0/ (c) (i) Open Access

\begin{abstract}
In India, the most common cancer among men is cancer of lip-oral and its incidence is further increasing. Nodal metastasis is an important prognostic factor in oral cancer. Previous studies on factors associated with nodal involvement are mainly focused on clinical exploration, and there is very little work in statistical modeling for nodal involvement. Also, the available studies have limited covariates and their varying forms. Further, studies available from India have mainly focused either on occult nodal metastasis only or a specific site of oral or stages. Hence, in order to identify epidemiological determinants of nodal metastasis, objective of this study was to develop a regression model to find out factors associated with nodal involvement and assess its validity. 945 histopathologically proven oral squamous cell carcinoma (OSCC) patients who went under surgery including neck dissection during 1995-2013 at the Department of Surgical Oncology, Dr. BRA-IRCH, AIIMS, New Delhi, India, were included for model building. Another data of $204 \mathrm{pa}-$ tients available during 2014-2015 was used for the temporal validation of the developed model. To assess the factors associated with nodal involvement, stepwise multivariable logistic regression procedure was used and results are presented as odds ratio and corresponding 95\% confidence interval (CI). Pain at the time of presentation [1.34 (1.02 to 1.77)], sub mucous fibrosis (SMF) [0.45 (0.21 to 0.95$)$ ], palpable neck node [2.38 (1.69 to 3.35)], tongue [1.63 (1.07 to 2.46)] as compared to buccal mucosa and degree of differentiation [1.41 (1.05 to 1.89)] were found to be significantly associated with nodal involvement. Further, diagnostic performance of the developed model was found to be satisfactory on temporal validation. These data suggest that, Pain at time of presentation, presence of clinical neck node, SMF, degree of differentiation and oral site are the most probable factors associated with nodal
\end{abstract}


involvement in OSCC.

\section{Keywords}

Oral Cancer, Oral Squamous Cell Carcinoma, Nodal Involvement, Metastasis, Epidemiological Model

\section{Introduction}

Cancer is a term used for diseases in which abnormal cells divide without control and are able to invade other tissues. All malignancies that are originated in the oral tissue are termed as oral cancer [1]. It mainly includes the Lips, Tongue, Alvelobuccal, Alveolus, RMT (Retromolar Triangle), Central arch (CA), Floor of mouth (FOM) and Buccal mucosa (BM). Squamous cell carcinoma (SCC) is most common histological type of cancer of the oral cavity and has an important and well-established pattern of dissemination to cervical lymph nodes [2].

According to GLOBOCAN 2012, an estimated 14.1 million new cancer cases and 8.2 million cancer-related deaths occurred in 2012 and projections based on the GLOBOCAN 2012 estimates predict a substantive increase to 19.3 million new cancer cases per year by 2025 . On the Indian scene, the five most common cancers were cancers of the breast, cervix uteri, lip-oral, lung and colorectum. Further, the most common cancer among Indian men is cancer of lip-oral [3]. Figure 1 shows the rank wise burden of oral cancer.

Oral cancer is evaluated at three levels, i.e., diagnosis of oral cancer, locoregional extent and systemic extent of oral cancer. As oral squamous cell carcinoma grows, cancer cells can spread to other parts of the body through the blood and lymph systems [4]. Metastasis to cervical lymph nodes may be because of filtering effect of the rich lymphatic system. Nodal metastasis strongly influences the five year survival rate, prognosis of oral cancer [5] and significantly affects regional control and survival [6] [7] [8] [9] [10]. Also, Metastasis in nodes is a complex multi-step process and cannot be explained by enlargementonly [11] [12].

The presence of cervical lymph node metastasis is clinically detected by palpation and assisted examinations such as computed tomography (CT) and magnetic resonance imaging (MRI) [13]. Among those having no clinically nodal involvement, up to $34 \%$ of the patient may still harbor occult metastasis [2] [5] [12] [13] [14] [15]. Further, only in about $40 \%$ of those having clinical nodal involvement may have metastasis. Until now, how this can be best managed remains unclear [11] [12] [16] [17].

In addition to the primary lesion, the presence or absence of metastasis in the cervical lymph nodes may also greatly influence the outcome of oral cancer. Hence, along with treating the primary lesion, appropriate management of the cervical lymph nodes is an important part of oral cancer therapy [12] [17] [18] 


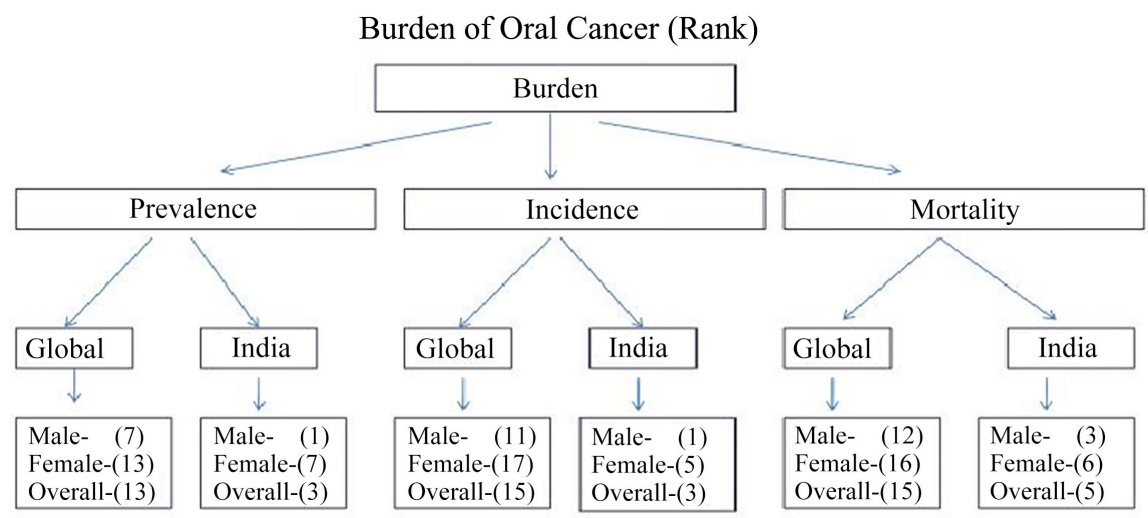

Figure 1. Burden of oral cancer.

[19] [20] [21]. Also, there has long been controversy over the indication, timing and methods of neck dissection [20] [21]. Latest in 2102, Dr. Deo also shows his concern regarding treatment of neck, on the data from same centre in Buccal and Alvelo-buccal cancer [12]. Difficulty in early diagnosis thus restricts the treatment carried out by surgeons [13]. A reliable and accurate means of preoperative evaluation of cervical lymph node metastasis is therefore crucial for the correct management of oral cancer [12] [18] [21] [22] [23]. Hence, establishment of an adequate therapeutic regimen is required through elucidation of possible factors involved in metastasis in the cervical lymph nodes in individual cases. Also, understanding of its associated factors may provide clues to the clinicians for better management. There are some studies reporting the factors associated with nodal involvement in oral cancer [2] [5] [23]-[32]. However, previous studies are mainly focused on clinical exploration, and there are very less work in statistical modeling for nodal involvement. Studies from India have mainly focused either on occult nodal metastasis only or a specific site of oral i.e., tongue, lip or buccal mucosa or stages. Also, they rely on small sample size, very limited covariates and only descriptive statistical analyses. Further, the considered number of covariates and scales of measurements of specific covariates vary from study to study. As obvious, such considerations are likely to provide varying results. In summary, to the best of my knowledge, there is no well organized study, especially from Indian population, in order to identify epidemiological determinants of nodal metastasis. Hence, objective of this study was to develop a regression model to find out the factors associated with nodal involvement and assess its temporal validity.

\section{Materials and Methods}

This was a cross-sectional study in which all histopathologically proven oral squamous cell carcinoma patients who went under surgery including neck dissection were included. One of the largestdatabase available on oral cancer patients attending to the outpatient department (OPD) of Department of Surgical Oncology, Institute Rotary Cancer Hospital (IRCH), All India Institute of Medical Sciences (AIIMS), New Delhi, India was used. The data were collected from 
existing files which is available in record section of the Institute. Accordingly, out of data of 1123 oral cancer patients collected during 1995 to 2013, 945 fulfilled the inclusion criteria and was used for regression model building. Another data set of 251 patients for the period from 2014-2015 were collected for validation (temporal) of the developed model. Out of them, only 204 could be used for validation in view of the required inclusion criteria. This study was approved by the Institute Ethics Committee of the All India Institute of Medical Sciences. The data of the oral cancer patients was managed using Microsoft Office Access (MS Access) software. Further, as a part of monthly audit, the cases seen in each month get updated in the database. Statistical software, STATA/SE version 14.2 (StataCorp LP, College Station, TX, USA), was used for analysis.

A proforma "IRCT-Surgical oncology proforma for oral cancer management" was developed to collect all the necessary information from the patients routinely attending to the outpatient department (OPD) of the Department of Surgical Oncology, IRCH, AIIMS, New Delhi. India. It includes all demographic information, clinical observation and histopathological information taken during the treatment. Covariates and there forms were chosen based on extensive review of literature, exploratory analysis, and discussion with clinicians.

To describe the distribution of categorical variables, absolute/relative frequency distribution was used. The association between two qualitative independent variables was assessed using chi square test/Fisher's exact test. Linear correlations were assessed by Pearson's correlation coefficient and monotonic correlation by Spearman's rank correlation coefficient [33]. To find out the factors associated with nodal involvement, stepwise multivariable logistic regression procedure was used. Out of available 39 covariates, a set of 19 covariates (gender, age, socioeconomic status (as reported by the patients/their attendant), pain at the time of presentation, duration of symptoms, leukoplakia, smoking, SMF, duration of risk, tumor growth type, clinical t-stage, trismus, skin involvement, bone involvement, oral cutaneous fistula (OCF), palpable neck node, oral site, degree of differentiation, and tumor size) were considered for model building based on their association at level of significance up to $25 \%$ under crude association analysis [34] and/or on its clinical relevance. Result is presented in the form of odds ratio and corresponding 95\% CI. Performance of the models was assessed using measures of discrimination and calibration (i.e. the correctness of the prediction probability of nodal involvement). Discrimination performance was evaluated using area under the curve (AUC) and correctly classified value. Calibration of the predicted probabilities calculated by the model was investigated using Hosmer-Lemeshow (HL) [35] goodness of fit test and specification error by linktest [36]. Internal validation was assessed using bootstrap simulation analysis [37] and temporal validation [38] was evaluated in relation to discrimination ability only.

\section{Results}

A total of 945 patients (model data) were included in the study for developing an 
epidemiological model for nodal involvement and another 204 patients for the temporal validation of the developed model. Majority of 945 patients were male and of age less than 60 years $(77.57 \%)$. Mean $( \pm S D)$ age of the patients was 50.73 $( \pm 12.46)$ years. Details of the Clinicopathological factors of the patients are presented in (Table 1).

Out of 19 covariates, 11 were found to be significant at the level of $25 \%$ under crude association analysis and 8 on the basis of their clinical relevance were taken as covariates for stepwise regression. As evident from analytical results under multivariable regression analysis, pain at the time of presentation, SMF, palpable neck node, oral site and degree of differentiation were found to be significantly associated factors with nodal involvement. The patients with pain at the time of presentation were 34 percent more likely to have nodal positivity [1.34 (1.03 to $1.74)]$, whereas oral site, tongue were 1.63 times more likely to have nodal positivity [1.63 (1.02 to 2.14)] with reference to the buccal mucosa. The detailed results under multivariable regression analysis were presented in (Table 2). Further, developed model could discriminate a case of nodal involvement with probability 0.65 (AUC $=0.65$ ) and \% of correctly classified patients was $65.61 \%$. Regarding internal validity under bootstrap simulation analysis (with replacement) considering thousand iterations, area under the curve was calculated $($ AUC $=0.65)$. This result indicates the satisfactory internal validity of the developed model. Also, HL goodness of fit test indicates that the model fits the data satisfactorily and there was no specification error under link test.

Under temporal validation data, the AUC of the developed model was 0.67 and $\%$ of correctly classified patients was $63.7 \%$. The analytical results listed in (Table 3 ) and plotted in (Figure 2) clearly indicate that there was no statistical significant difference of diagnostic performance (AUC) of developed model on temporal validation data $(\mathrm{p}=0.58)$.

\section{Discussion}

Neck node metastasis is an important prognostic factor in oral SCC. Incidence of nodal involvement varies from $35.3 \%$ to $60 \%$ in the patients with OSCC, however $15 \%-34 \%$ of patients with a clinical N0 neck may still harbor occult metastasis [2] [5] [12] [13] [14] [15]. Its management however remains unclear [11] [17] [23] and which was also focused by Dr. Deo (2012) on the data from the same centre [12]. In the present study, nodal involvement was found in $39.8 \%$ of the cases. In patients with clinical positive nodes, $55.9 \%$ of patients did not have pathologically positive nodes. Also, in patients with clinical negative nodes, $26.6 \%$ of patients had pathologically positive nodes. In other words, occult nodes were found in $26.6 \%$ of the cases.

As indicated earlier, most of the earlier studies are clinical exploration rather than statistical modeling and dealt with different study population. Further, none of the earlier studies have dealt with either the total number of covariates considered in the present study or their considered scale of measurements. Also, 
Table 1. Covariates features of 945 OSCC patients and association with cervical lymph node metastasis.

\begin{tabular}{|c|c|c|c|c|c|}
\hline \multicolumn{2}{|c|}{ Variables } & \multirow{3}{*}{$\begin{array}{c}\text { pNodes (+) } \\
\text { N (\%) } \\
96(45.3) \\
280(38.2)\end{array}$} & \multirow{3}{*}{$\begin{array}{c}\text { pNodes (-) } \\
\text { N (\%) } \\
116(54.7) \\
453(61.8)\end{array}$} & \multirow{3}{*}{$\begin{array}{c}\text { Total } \\
\text { N (\%) } \\
212(22.4) \\
733(77.6)\end{array}$} & \multirow{3}{*}{$\begin{array}{c}\text { p-value } \\
0.063\end{array}$} \\
\hline \multirow[t]{2}{*}{ Gender } & Female & & & & \\
\hline & Male & & & & \\
\hline Age & $<40$ & $71(38.6)$ & $113(61.4)$ & $184(19.5)$ & \multirow{3}{*}{0.481} \\
\hline (years) & $40-60$ & $227(41.4)$ & $322(58.6)$ & $549(58.1)$ & \\
\hline \multirow{5}{*}{ Soc-Eco Status } & $>60$ & $78(36.8)$ & $134(63.2)$ & $212(22.4)$ & \\
\hline & LC & $101(40.1)$ & $151(59.9)$ & $252(26.7)$ & \multirow{4}{*}{0.559} \\
\hline & LMC & $190(38.1)$ & 309 (61.9) & $499(52.8)$ & \\
\hline & UMC & $77(44.3)$ & $97(55.7)$ & $174(18.4)$ & \\
\hline & UC & $8(40.0)$ & $12(60.0)$ & $20(2.1)$ & \\
\hline \multirow[t]{2}{*}{ Pain } & No & $191(36.7)$ & $330(63.3)$ & $521(55.1)$ & \multirow{2}{*}{0.029} \\
\hline & Yes & $185(43.6)$ & $239(56.4)$ & $424(44.9)$ & \\
\hline \multirow{3}{*}{$\begin{array}{c}\text { Dur. of Symp. } \\
\text { (months) }\end{array}$} & $<3$ & $104(41.6)$ & $146(58.4)$ & $250(26.5)$ & \multirow{3}{*}{0.214} \\
\hline & $\geq 3 \&<6$ & $156(41.9)$ & $216(58.1)$ & $372(39.4)$ & \\
\hline & $\geq 6$ & $116(35.9)$ & $207(64.1)$ & $323(34.1)$ & \\
\hline \multirow[t]{2}{*}{ Leukoplakia } & No & $349(40.5)$ & $513(59.5)$ & $862(91.2)$ & \multirow{2}{*}{0.157} \\
\hline & Yes & $27(32.5)$ & $56(67.5)$ & $83(8.8)$ & \\
\hline \multirow[t]{2}{*}{ Smoking } & No & $250(42.2)$ & $342(57.8)$ & $592(62.6)$ & \multirow{2}{*}{0.047} \\
\hline & Yes & $126(35.7)$ & $227(64.3)$ & $353(37.4)$ & \\
\hline \multirow[t]{2}{*}{ SMF } & No & $366(40.5)$ & $538(59.5)$ & $904(95.7)$ & \multirow{2}{*}{0.039} \\
\hline & Yes & $10(24.4)$ & $31(75.6)$ & $41(4.3)$ & \\
\hline Dur. Risk & 0 & $69(42.6)$ & $93(57.4)$ & $162(17.2)$ & \multirow{5}{*}{0.306} \\
\hline \multirow[t]{4}{*}{ (months) } & $\leq 60$ & $40(43.5)$ & $52(56.5)$ & $92(9.7)$ & \\
\hline & $>60 \& \leq 120$ & $104(43.3)$ & $136(56.7)$ & $240(25.4)$ & \\
\hline & $>120 \& \leq 240$ & $95(36.3)$ & $167(63.7)$ & $262(27.7)$ & \\
\hline & $>240$ & $68(36.0)$ & $121(64.0)$ & $189(20.0)$ & \\
\hline \multirow[t]{3}{*}{ Tumor Growth } & UIG & $165(42.8)$ & $221(57.2)$ & $386(40.8)$ & \multirow{3}{*}{0.294} \\
\hline & UPG & 204 (37.9) & $335(62.1)$ & $539(57.0)$ & \\
\hline & Other & $7(35.0)$ & $13(65.0)$ & $20(2.2)$ & \\
\hline \multirow[t]{4}{*}{ cT-Stage } & $\mathrm{T} 1$ & $29(36.3)$ & $51(63.7)$ & $80(8.5)$ & \multirow{4}{*}{0.729} \\
\hline & $\mathrm{T} 2$ & $107(42.5)$ & $145(57.5)$ & $252(26.7)$ & \\
\hline & $\mathrm{T} 3$ & $38(38.4)$ & $61(61.6)$ & $99(10.5)$ & \\
\hline & $\mathrm{T} 4$ & $202(39.3)$ & $312(60.7)$ & $514(54.3)$ & \\
\hline \multirow[t]{2}{*}{ Trismus } & No & 287 (39.6) & $437(60.4)$ & $724(76.6)$ & \multirow{2}{*}{0.867} \\
\hline & Yes & $89(40.3)$ & $132(59.7)$ & $221(23.4)$ & \\
\hline cSkin Inv & No & $292(40.5)$ & $429(59.5)$ & $721(76.3)$ & 0 \\
\hline & Yes & $84(37.5)$ & $140(62.5)$ & $224(23.7)$ & $0.42 J$ \\
\hline OCF & No & $367(40.1)$ & $549(59.9)$ & $916(96.9)$ & \\
\hline & Yes & $9(31.0)$ & $20(69.0)$ & $29(3.1)$ & 0.020 \\
\hline
\end{tabular}




\section{Continued}

\begin{tabular}{cccccc}
\hline cBone Inv & No & $268(38.6)$ & $426(61.4)$ & $694(73.4)$ & 0.221 \\
cNeck Node & Yes & $108(43.0)$ & $143(57.0)$ & $251(26.6)$ & \\
& No & $62(26.6)$ & $171(73.4)$ & $233(24.7)$ & $\leq 0.001$ \\
Oral Site & Yes & $314(44.1)$ & $398(55.9)$ & $712(75.3)$ & \\
& BM & $97(35.7)$ & $175(64.3)$ & $272(28.7)$ & \\
& Tongue & $90(45.0)$ & $110(55.0)$ & $200(21.3)$ & \\
& Alvelobuccal & $77(43.5)$ & $100(56.5)$ & $177(18.7)$ & \\
& Alveolus & $45(43.3)$ & $59(56.7)$ & $104(11.0)$ & 0.093 \\
& CA \& FOM & $28(31.1)$ & $62(68.9)$ & $90(9.5)$ & \\
& RMT & $17(31.5)$ & $37(68.5)$ & $54(5.7)$ & \\
Deg. of Diff. & Lip & $22(45.8)$ & $26(54.2)$ & $48(5.1)$ & \\
& WD & $248(37.7)$ & $410(62.3)$ & $658(69.6)$ & \multirow{2}{*}{0.046} \\
Tumor Size & Others & $128(44.6)$ & $159(55.4)$ & $287(30.4)$ & \\
(cm) & $\leq 2$ & $91(35.6)$ & $165(64.4)$ & $256(27.1)$ & \\
& $>2$ and $\leq 4$ & $196(42.1)$ & $270(57.9)$ & $466(49.3)$ & 0.231 \\
& $>4$ & $89(39.9)$ & $134(60.1)$ & $223(23.6)$ & \\
\hline
\end{tabular}

LC, Lower class; LMC, Lower middle class; UC, Upper class; UMC, Upper middle class; UIG, Ulceroinfiltrative; UPG, ulceroproliferative; WD, Well Differentiated; Deg. of Diff., Degree of differentiation; cSkin Inv, clinical skin involvement; cBone Inv, clinical bone involvement; SMF, sub mucous fibrosis.

Table 2. Results under multivariable analysis of clinicopathological factors for cervical lymph nodal metastasis.

\begin{tabular}{|c|c|c|c|c|c|c|}
\hline \multicolumn{2}{|c|}{ Variables } & \multirow{2}{*}{$\begin{array}{l}\text { Freq (\%) } \\
521(55.1)\end{array}$} & \multirow{2}{*}{$\begin{array}{c}\text { UOR } \\
1\end{array}$} & \multirow[t]{2}{*}{$(95 \% \mathrm{CI})$} & \multirow{2}{*}{$\begin{array}{c}\text { AOR }^{*} \\
1\end{array}$} & \multirow[t]{2}{*}{$(95 \% \mathrm{CI})$} \\
\hline Pain & No & & & & & \\
\hline & Yes & $424(44.9)$ & 1.34 & (1.03 to 1.74 ) & 1.34 & (1.02 to 1.77$)$ \\
\hline \multirow[t]{2}{*}{ cNeck Node } & No & $233(24.7)$ & 1 & & 1 & \\
\hline & Yes & $712(75.3)$ & 2.18 & (1.57 to 3.01 ) & 2.38 & (1.69 to 3.35$)$ \\
\hline \multirow[t]{2}{*}{ SMF } & No & $904(95.7)$ & 1 & & 1 & \\
\hline & Yes & $41(4.3)$ & 0.47 & (0.23 to 0.98$)$ & 0.45 & (0.21 to 0.95$)$ \\
\hline \multirow[t]{7}{*}{ Oral Site } & $\mathrm{BM}$ & $272(28.7)$ & 1 & & 1 & \\
\hline & Tongue & $200(21.3)$ & 1.48 & (1.02 to 2.14 ) & 1.63 & (1.07 to 2.46$)$ \\
\hline & Alvelobuccal & $177(18.7)$ & 1.39 & (0.94 to 2.05 ) & 1.17 & (0.78 to 1.77$)$ \\
\hline & Alveolus & $104(11.0)$ & 1.38 & (0.87 to 2.18$)$ & 1.22 & (0.75 to 1.99$)$ \\
\hline & CA \& FOM & $90(9.5)$ & 0.81 & (0.49 to 1.36$)$ & 0.65 & (0.37 to 1.13$)$ \\
\hline & RMT & $54(5.7)$ & 0.83 & (0.44 to 1.55$)$ & 0.76 & (0.40 to 1.45$)$ \\
\hline & Lip & $48(5.1)$ & 1.53 & (0.82 to 2.84 ) & 1.90 & (0.99 to 3.64$)$ \\
\hline \multirow[t]{2}{*}{ Deg. of Diff. } & WD & $658(69.6)$ & 1 & & 1 & \\
\hline & Others & $287(30.4)$ & 1.33 & (1.01 to 1.76$)$ & 1.41 & (1.05 to 1.89$)$ \\
\hline
\end{tabular}

UOR, Unadjusted odds ratio; AOR, Adjusted odds ratio. *Adjusted in relation to smoking, duration of risk, tumor growth type and clinical bone involvement. 
Table 3. Comparison of AUC for model and validation data.

\begin{tabular}{cccccc}
\hline Data & Observation & AUC & Std. Err. & $95 \%$ CI & P value \\
\hline Model Data & 904 & 0.65 & 0.02 & 0.61 to 0.68 & \\
Validation Data & 204 & 0.67 & 0.04 & 0.60 to 0.75 & 0.58 \\
\hline
\end{tabular}

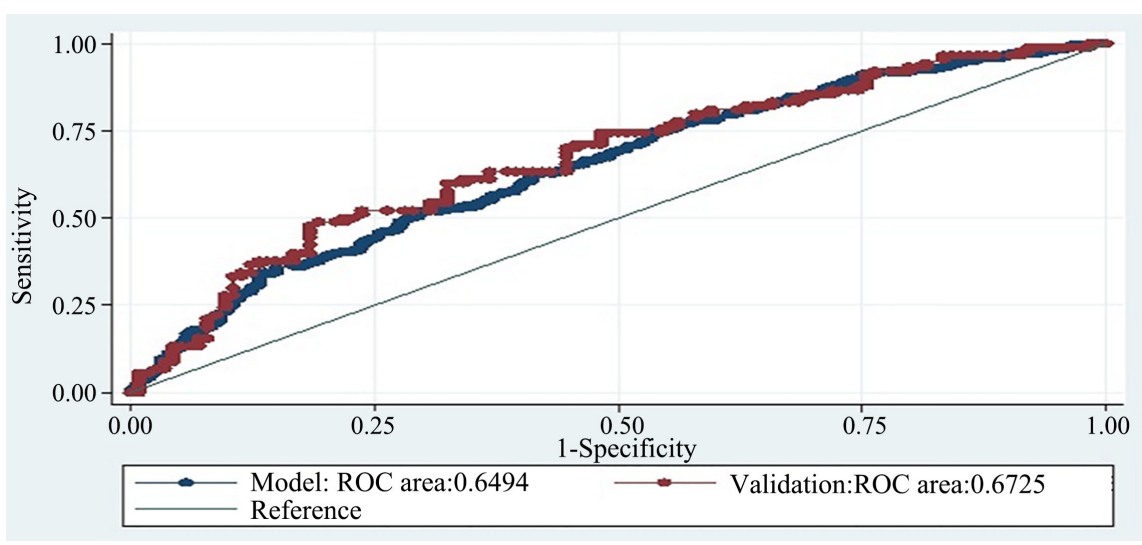

Figure 2. Comparative receiver operating curves for model and validation data.

this is the first study to validate (temporal) the performance of developed logistic model to discriminate nodal involvement and non involvement. Hence, there is little scope to compare the findings under the present study with those reported in earlier studies. However, for completeness, a brief discussion is listed here considering only reported significantly associated covariates with nodal involvement.

For an instance, Robert M. Byers et al. (1998) developed a predictive model for nodal metastasis and found that depth of muscle invasion, clinical $\mathrm{N}$ stage and tumor differentiation were significantly associated with nodal metastasis in tongue carcinoma on 91 patients [29]. Further, Jose Guilherme Vartanian et al. (2004) evaluated the predictive factors of lymph node metastasis in only lip cancer patients and found that commissure involvement and T3/T4 stage were significantly associated. They studied only three variables under univariate analysis and also they use those samples in which even neck dissection not have done [39]. In another study, Masaaki Karino et al. (2014) performed preoperative nuclear morphometry for OSCC cells in tongue, gingival, buccal mucosa and mouth floor and reported nuclear area and nuclear perimeter as risk factors. However, primary tumor site was not found to be associated with cervical lymph node metastasis under multivariable regression analysis on 88 patients only collected retrospectively from 1981 to 2012 [5]. Under another study (Kailiu Wu et al. (2015)) histological grade and neurovascular invasion were associated with the risk of cervical lymph node metastasis of early tongue SCC $(n=171)$ [13]. Further, Punnaya V. Angadi et al. (2015) found tumor budding and depth of invasion as significant predictors for lymph node metastasis in OSCC through multivariable regression analysis on merely 75 patients [40]. Furthermore, Siri- 
wardeba et al. (2016) reported a comparison of metastasis (positive or negative) with sex, various age group and different oral sites and found that oral site was significantly associated with metastasis. Even they utilized 989 OSCC patients information, but the number of covariates was only three. The information regarding other important covariates like stage etc. was not available in the study [41].

In the present study, nodal involvement was examined histopathologically in patients with OSCC in order to elucidate the factors involved. In addition to already reported predictive factors namely palpable neck node, degree of differentiation and oral site for nodal metastasis under earlier studies, pain at the time of presentation and SMF were also found associated with nodal metastasis. Accordingly, along with the palpable neck node, in decision making regarding level of neck dissection, one may also consider pain, SMF, degree of differentiation and oral sites.

Further, an extensive discussion with clinical experts led to understand the protective behavior of SMF. This can be explained based on the hypothesis of fibrosis blocking lymphatic leading to less nodal involvement. In 2012, Pankaj Chaturvedi et al. published an article on Indian OSCC patients to see the clinicopathological differences between with and without oral SMF. He found that patients with oral cancer-OSMF were less likely to present with a metastatic neck node [42]. Again, Gaurav Singh et al. (2014), reported that negative neck node was significantly more in oral SMF patients with T4 lesions. In T1, T2 and T3 lesions, positive neck node was more among non-OSMF patients, but difference was statistically non-significant [43]. In both the studies, author used only univariate analysis. However, the relation of OSMF behavior with nodal involvement was on same pattern, what we got in our study.

It is strength of the present study that the development of model and its validity testing utilized a large scale data involving clinically relevant covariates. In view of this, the results under present study are likely to be of optimal use.

However, in view of observed moderate predictive ability of the developed model this model could also not be able to predict nodal metastasis with greater accuracy, hence a multicentre large scale study involving all possible relevant covariates may be a better choice.

In conclusion, findings under the present study reveals that, pain at the time of presentation, presence of clinical neck node, sub mucous fibrosis, degree of differentiation and oral site are the most probable factors associated with nodal involvement in oral squamous cell carcinoma patients. The current results might be expected to guide the clinical practices more accurately.

\section{Acknowledgements}

Thanks to the members of Doctoral Committee to review the ongoing Ph.D. work of VS periodically and on required points. Also thanks to All India Institute of Medical Sciences for providing the facilities. 


\section{Conflicts of Interest}

The authors declare no conflicts of interest regarding the publication of this paper.

\section{References}

[1] Prabhu, S.R., Johnson, N.W., Daftary, D.K. and Wilson, D.F. (1992) Oral Diseases in the Tropics. Oxford University Press, Oxford.

[2] Pimenta Amaral, T.M., Da Silva Freire, A.R., Carvalho, A.L., Pinto, C.A.L. and Kowalski, L.P. (2004) Predictive Factors of Occult Metastasis and Prognosis of Clinical Stages I and II Squamous Cell Carcinoma of the Tongue and Floor of the Mouth. Oral Oncology, 40, 780-786. https://doi.org/10.1016/j.oraloncology.2003.10.009

[3] World Health Organization. International Agency for Research on Cancer. GLOBOCAN2012. http://globocan.iarc.fr/Default.aspx

[4] National Cancer Institute. http://www.cancer.gov/about-cancer/understanding/what-is-cancer.

[5] Karino, M., Nakatani, E., Hideshima, K., Nariai, Y., Tsunematsu, K., Ohira, K., et al. (2014) Applicability of Preoperative Nuclear Morphometry to Evaluating Risk for Cervical Lymph Node Metastasis in Oral Squamous Cell Carcinoma. PLoS One, 9, 1-15. https://doi.org/10.1371/journal.pone.0116452

[6] De Matos, L.L., Manfro, G., Dos Santos, R.V., Stabenow, E., De Mello, E.S., Alves, V.A.F., et al. (2014) Tumor Thickness as a Predictive Factor of Lymph Node Metastasis and Disease Recurrence in T1N0 and T2N0 Squamous Cell Carcinoma of the Oral Tongue. Oral Surgery, Oral Medicine, Oral Pathology, Oral Radiology, 118, 209-217. https://doi.org/10.1016/j.oooo.2014.03.023

[7] Warburton, G., Nikitakis, N.G., Roberson, P., Marinos, N.J., et al. (2007) Histopathological and Lymphangiogenic Parameters in Relation to Lymph Node Metastasis in Early Stage Oral Squamous Cell Carcinoma. Journal of Oral and Maxillofacial Surgery, 65, 475-484. https://doi.org/10.1016/j.joms.2005.12.074

[8] Méndez, E., Fan, W., Choi, P., Agoff, N., Whipple, M., Farwell, D.G., et al. (2007) Tumor-Specific Genetic Expression Profile Of Metastatic Oral Squamous Cell Carcinoma. Head \& Neck, 29, 803-814. https://doi.org/10.1002/hed.20598

[9] Massano, J., Regateiro, F.S., Januário, G. and Ferreira, A. (2006) Oral Squamous Cell Carcinoma: Review of Prognostic and Predictive Factors. Oral Surgery, Oral Medicine, Oral Pathology, Oral Radiology, 102, 67-76. https://doi.org/10.1016/j.tripleo.2005.07.038

[10] Okura, M., Iida, S., Aikawa, T., Adachi, T., Yoshimura, N. and Yamada, T. (2008) Tumor Thickness and Paralingual Distance of Coronal MR Imaging Predicts Cervical Node. American Journal of Neuroradiology, 29, 45-50. https://doi.org/10.3174/ajnr.A0749

[11] Nathanson, S.D. (2003) Insights into the Mechanisms of Lymph Node Metastasis. Cancer, 98, 413-423. https://doi.org/10.1002/cncr.11464

[12] Deo, S.V.S., Shukla, N.K. and Jha, D. (2012) Are We Over-treating Neck in Buccal \& Alveolo-Buccal Cancers: Experience from a Tertiary Cancer Care Center. Indian Journal of Surgical Oncology, 3, 272-275. https://doi.org/10.1007/s13193-012-0173-Z

[13] Wu, K., Yang, X., Li, L., Ruan, M., Liu, W. and Lu, W. (2015) Neurovascular Invasion and Histological Grade Serve as the Risk Factors of Cervical Lymph Node Metastases in Early Tongue Squamous Cell Carcinoma. Molecular Neurobiology, 53, 2920-2926. https://doi.org/10.1007/s12035-015-9175-5 
[14] Van Der Brekel, M.W.M., Van Der Waal, I., Meijer, C.J.L.M., Freeman, J.L. and Snow, G.B. (1996) The Incidence of Micrometastases in Neck Dissection Specimens Obtained From Elective Neck Dissections. The Laryngoscope, 106, 987-991. https://doi.org/10.1097/00005537-199608000-00014

[15] Noguti, J., De Moura, C.F., De Jesus, G.P., Da Silva, V.H., Hossaka, T.A., Oshima, C.T. and Ribeiro, D.A. (2012) Metastasis from Oral Cancer: An Overview. Cancer Genomics Proteomics, 336, 329-335.

[16] Fasunla, A.J., Greene, B.H., Timmesfeld, N., Wiegand, S., Werner, J.A. and Sesterhenn, A.M. (2011) A Meta-Analysis of the Randomized Controlled Trials on Elective Neck Dissection versus Therapeutic Neck Dissection in Oral Cavity Cancers with Clinically Node-Negative Neck. Oral Oncology, 47, 320-324.

https://doi.org/10.1016/j.oraloncology.2011.03.009

[17] Hoch, S., Fasunla, J., Eivazi, B., Werner, J.A. and Teymoortash, A. (2012) Delayed Lymph Node Metastases after Elective Neck Dissection in Patients with Oral and Oropharyngeal Cancer and pN0 Neck. Journal of Otolaryngology-Head \& Neck Surgery, 33, 505-509.

[18] Kim, K.-Y. and Cha, I.-H. (2011) A Novel Algorithm for Lymph Node Status Prediction of Oral Cancer before Surgery. Oral Oncology, 47, 1069-1073.

[19] Lim, Y.C., Koo, B.S., Lee, J.S. and Choi, E.C. (2006) Level V Lymph Node Dissection in Oral and Oropharyngeal Carcinoma Patients with Clinically Node-Positive Neck: Is It Absolutely Necessary? Laryngoscope, 116, 1232-1235.

[20] Montes, D.M., Carlson, E.R., Fernandes, R., Ghali, G.E., Lubek, J., Ord, R., et al. (2011) Oral Maxillary Squamous Carcinoma: An Indication for Neck Dissection in the Clinically Negative Neck. Head Neck, 33, 1581-1585. https://doi.org/10.1002/hed.21631

[21] Liao, C., Hsueh, C., Lee, L., Lin, C., Fan, K. and Wang, H. (2012) Neck Dissection Field and Lymph Node Density Predict Prognosis in Patients with Oral Cavity Cancer and Pathological Node Metastases Treated with Adjuvant Therapy. Oral Oncology, 48, 329-336.

[22] Kang, C., Liao, C., Hsueh, C., Lee, L., Lin, C. and Fan, K. (2011) Outcome Analysis of Patients with Well-Differentiated Oral Cavity Squamous Cell Carcinoma. Oral Oncology, 47, 1085-1091.

[23] Sekine, J., Uehara, M., Hideshima, K., Irie, A. and Inokuchi, T. (2003) Predictability of Lymph Node Metastases by Preoperative Nuclear Morphometry in Squamous Cell Carcinoma of the Tongue. Cancer Detection and Prevention, 27, 427-433. https://doi.org/10.1016/j.cdp.2003.09.001

[24] Briggs, R.J.S., Pienta, K.J., Hruban, H. and William, J. (1992) Nuclear Morphometry for Prediction of Metastatic Potential in Early Squamous Cell Carcinoma of the Floor of the Mouth Squamous. Archives of Otolaryngology_Head and Neck Surgery, 118, 531-533. https://doi.org/10.1001/archotol.1992.01880050085020

[25] Chone, C.T., Aniteli, M.B., Magalhães, R.S., Freitas, L.L., Altemani, A., Ramos, C.D., et al. (2013) Impact of Immunohistochemistry in Sentinel Lymph Node Biopsy in Head and Neck Cancer. European Archives of Oto-Rhino-Laryngology, 270, 313-317. https://doi.org/10.1007/s00405-012-2032-5

[26] Lim, S., Zhang, S., Ishii, G., Endoh, Y., Kodama, K., Miyamoto, S., et al. (2004) Predictive Markers for Late Cervical Metastasis in Stage I and II Invasive Squamous Cell Carcinoma of the Oral Tongue. Clinical Cancer Research, 10, 166-172.

[27] Kawano, K. and Yanagisawa, S. (2006) Original Article Predictive Value of Laminin-5 and Membrane Type 1-Matrix Metalloproteinase Expression for Cervical 
Lymph Node Metastasis in T1 and T2 Squamous Cell Carcinomas of the Tongue and Floor of the Mouth. Head and Neck, 28, 525-533.

[28] Harada, H., Medical, T., Omura, K., General, T., Nakajima, Y. and Medical, T. (2006) Cyclin B1 Is Useful to Predict Occult Cervical Lymph Node Metastases in Tongue Carcinoma Cyclin B1 Is Useful to Predict Occult Cervical Lymph Node Metastases in Tongue Carcinoma. Journal of Experimental \& Clinical Cancer Research, 25, 351-356.

[29] Byers, R.M., El-Naggar, A.K., Lee, Y.Y., Rao, B., Fornage, B., Terry, N.H., et al. (1998) Can We Detect or Predict the Presence of Occult Nodal Metastases in Patients with Squamous Carcinoma of the Oral Tongue? Head Neck, 20, 138-144.

[30] d’Alessandro, A.F., Pinto, F.R., Lin, C.S., Kulcsar, M.A.V., Cernea, C.R., Brandão, L.G., et al. (2015) Oral Cavity Squamous Cell Carcinoma: Factors Related to Occult Lymph Node Metastasis. Brazilian Journal of Otorhinolaryngology, 81, 248-254. https://doi.org/10.1016/j.bjorl.2015.03.004

[31] Kowalski, L.P. and Sanabria, A. (2007) Elective Neck Dissection in Oral Carcinoma: A Critical Review of the Evidence. Acta Otorrinolaringologica, 27, 113-117. http://www.pubmedcentral.nih.gov/articlerender.fcgi?artid=2640044\&tool=pmcent rez\&rendertype $=$ abstract

[32] Suzuki, M., Suzuki, T., Asai, M., Ichimura, K.I., Nibu, K.I., Sugasawa, M., et al. (2007) Clinicopathological Factors Related to Cervical Lymph Node Metastasis in a Patient with Carcinoma of the Oral Floor. Acta Otorrinolaringologica, 127, 129-135. https://doi.org/10.1080/03655230701600020

[33] Sundaram, K.R., Dwivedi, S.N. and Sreenivas, V. (2015) Medical Statistics Principles \& Methods. 2nd Edition, Wolter Kluwer, Alphen aan den Rijn.

[34] Bursac, Z., Gauss, C.H., Williams, D.K. and Hosmer, D.W. (2008) Purposeful Selection of Variables in Logistic Regression. Source Code for Biology and Medicine, 3, 17. https://doi.org/10.1186/1751-0473-3-17

[35] Hosmer, D. (1980) A Goodness-of-Fit Test of the Multiple Logistic Regression Model. Communication in Statistics-Theory and Methods, 9, 1043-1069.

[36] Scott Long, J. and Freese, J. (2014) Regression Models for Categorical Dependent Variables Using Stata. 3rd Edition, Stata Press, College Station.

[37] Harrell, F.E. (2015) Regression Modeling Strategies. 2nd Edition, Springer, Berlin.

[38] Altman, D.G. and Royston, P. (2000) What Do We Mean by Validating a Prognistic Model? Statistics in Medicine, 19, 453-473.

[39] Vartanian, J.G., Carvalho, A.L., de Araújo Filho, M.J., Junior, M.H., Magrin, J. and Kowalski, L.P. (2004) Predictive Factors and Distribution of Lymph Node Metastasis in Lip Cancer Patients and Their Implications on the Treatment of the Neck. Oral Oncology, 40, 223-227. https://doi.org/10.1016/j.oraloncology.2003.08.007

[40] Angadi, P.V., Patil, P.V., Hallikeri, K., Mallapur, M.D., Hallikerimath, S. and Kale, A.D. (2015) Tumor Budding Is an Independent Prognostic Factor for Prediction of Lymph Node Metastasis in Oral Squamous Cell Carcinoma. International Journal of Surgical Pathology, 23, 102-110. https://doi.org/10.1177/1066896914565022

[41] Samarakoon, B., Samadarani, M. and Mudiynaselage, R. (2016) Predictive Model of Oral Cancer Metastasis for Different Cancer Sites and Age Groups. Journal of Investigative and Clinical Dentistry, 7, 127-131.

[42] Chaturvedi, P., Vaishampayan, S.S., Nair, S., Nair, D., Agarwal, J.P. and Kane, S.V. (2013) Oral Squamous Cell Carcinoma Arising in Background of Oral Submucous Fibrosis: A Clinicopathologically Distinct Disease. Head Neck, 35, 1404-1409. 
[43] Singh, G., Singh, A., Kumar, A., Prajapati, A., Kumar, S. and Singh, P. (2017) Nodal Involvement in Oral Squamous Cell Carcinoma (SCC) Patients with and without Oral Sub Mucous Fibrosis (OSMF): A Comparative Study. Journal of Oral Biology and Craniofacial Research, 7, 171-177. https://doi.org/10.1016/j.jobcr.2017.03.007 